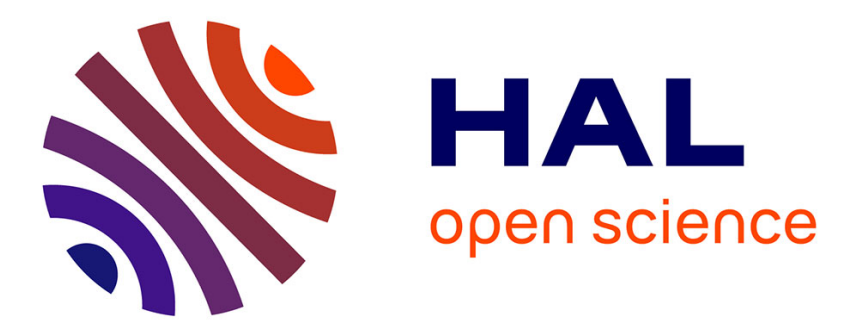

\title{
Nonlinear dynamics and Modulation Properties of Optically Injected Quantum Cascade Lasers
}

\author{
Cheng Wang, Frédéric Grillot, Vassilios Kovanis, Jacky Even
}

\section{To cite this version:}

Cheng Wang, Frédéric Grillot, Vassilios Kovanis, Jacky Even. Nonlinear dynamics and Modulation Properties of Optically Injected Quantum Cascade Lasers. Conference on Lasers and Electro-Optics Europe and International Quantum Electronics Conference 2013 (CLEO-Europe/IQEC 2013), May 2013, Munich, Germany. pp.CB-2.5, 10.1109/CLEOE-IQEC.2013.6800695 . hal-00827695

\section{HAL Id: hal-00827695 \\ https://hal.science/hal-00827695}

Submitted on 31 May 2013

HAL is a multi-disciplinary open access archive for the deposit and dissemination of scientific research documents, whether they are published or not. The documents may come from teaching and research institutions in France or abroad, or from public or private research centers.
L'archive ouverte pluridisciplinaire HAL, est destinée au dépôt et à la diffusion de documents scientifiques de niveau recherche, publiés ou non, émanant des établissements d'enseignement et de recherche français ou étrangers, des laboratoires publics ou privés. 


\title{
Nonlinear dynamics and Modulation Properties of Optically Injected Quantum Cascade Lasers
}

\author{
Cheng Wang ${ }^{1}$, Frédéric Grillot ${ }^{2}$, Vassilios Kovanis ${ }^{3}$, Jacky Even ${ }^{I}$ \\ 1. Université Européenne de Bretagne, INSA, CNRS FOTON, 20 avenue des buttes de Coesmes, 35708 Rennes Cedex 7, France \\ 2. Telecom Paristech, Ecole Nationale Supérieure des Télécommunications, CNRS LTCI, 46 rue Barrault, 75013 Paris, France \\ 3. ElectroScience Laboratory, Ohio State University, 1320 Kinnear Road, Columbus, OH, 43212, USA
}

Quantum cascade (QC) lasers have been of great interest since its first demonstration at Bell labs in 1994 [1]. In contrast to interband semiconductor lasers, one of the fundamental features in QC lasers is that the stimulated emission relies on the intersubband transition, which is dominated by the ultra-fast electron-optical phonon scattering mechanism within several picoseconds. Flat modulation responses without relaxation-oscillation resonance and high 3-dB bandwidths of about tens of gigahertz have been demonstrated experimentally [2]. It is well known that optical injection can well enhance the dynamical properties of semiconductor lasers. To this end, Meng et al studied the modulation responses of injection-locking QC lasers employing a simple two-level rate equation model, where the non-existence of the unstable locking region in the locking regime was pointed out [3]. However, we remark that this conclusion needs further investigation using a more accurate rate equation model and an explicit approach based on the analysis of the local bifurcation scenario.

In this work, we theoretically investigate the nonlinear and modulation properties of injection-locked QC lasers by taking into account the upper and lower subbands as well as the bottom state in the gain stage. In order to obtain the stable injection-locking regime both the saddle-node (SN) and the Hopf bifurcations are studied [4]. The bifurcations are calculated via the so-called numerical continuation, which is a powerful method for bifurcation analysis. As shown in figure 1(a), the stable locking regime is bounded by the supercritical bifurcations (thick lines). Like interband lasers, the regime is found to be enlarged with the injection level. However, the positions of the codimension-two points $\left(G_{1}, G_{2}\right)$, around which the laser is known to generate various nonlinear dynamics, move to higher injection levels. The influence of the linewidth enhancement factor (LEF), which is known to have significant impacts on the bifurcation diagram, will be also presented. Following the standard approach of linearizing the rate equations, we have obtained the modulation transfer function with which the modulation response is analyzed. The 3-dB bandwidth increases with the injection level as the interband laser case. However, it is stressed that no frequency dip occurs in the modulation response, which is a crucial point for broadband applications. The mechanism of this phenomenon is analyzed via the poles and zeros in the modulation transfer function with respect to the Bode plot. Figure 1(b) presents the frequency detuning effect on the QC laser: both positive and negative detunings enhance the modulation bandwidth.
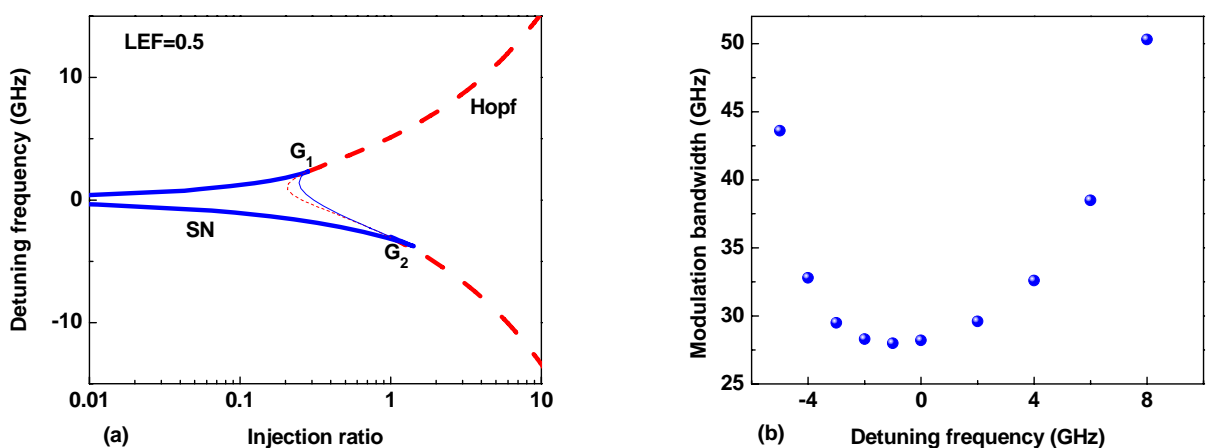

Fig. 1(a) Bifurcation diagram and stable locking regime of an injection-locked QC laser. Solid line is the SN bifurcation and dashed line is the Hopf bifurcation. Supercritical (subcritical) bifurcation is denoted by thick (thin) line. The stable locking regime is bounded by the supercritical bifurcations. (b) Calculated modulation bandwidth as a function of the detuning frequency of the QC laser.

Finally, an upgraded numerical model taking into account the multistage cascade scheme where electrons are recycled from period to period will be also presented. Furthermore, the influences of carrier lifetimes in the QC laser on the injection-locking dynamics will be discussed as well.

\section{References}

[1] J. Faist, F. Capasso, D. L. Sivco, C. Sirtori, A. L. Hutchinson, and A. Y. Cho, “Quantum cascade laser,” Science 264, 553-556 (1994).

[2] W. Maineult, L. Ding, P. Gellie, P. Filloux, and C. Sirtori, "Microwave modulation of terahertz quantum cascade lasers: a transmissionline approach,” Appl. Phys. Lett. 96, 021108 (2010).

[3] B. Meng, and Q. J. Wang, “Theoretical investigation of injection-locked high modulation bandwidth quantum cascade lasers,” Optics Express 20, 1450-1464 (2012).

[4] S. Wieczorek, B. Krauskopf, T. B. Simpson, and D. Lentsra, "The dynamical complexity of optically injected semiconductor lasers," Physics Reports 416, 1-128 (2005). 